\title{
The Predictive Ability of Social Anxiety within Internet Addiction among
} University Students

'Assistant Professor of Psychological and Educational Counseling, Faculty of Educational Sciences, The Hashemllite University, Zarqa, Jordan.

Email:drbassam69@yahoo.com

'Associate Professor, Educational Psychology, The Ministry of Education, Jordan.

${ }^{3}$ Professor of Educational Psychology, Al-Balqa Applied University, Jordan.

"Associate Professor of Educational Psycholog, College of Education, Prince Sattam bin Abdulaziz and Sohag

University, Egypt.

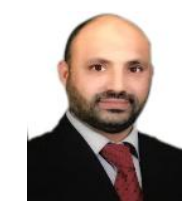

( Corresponding Author)

\section{Abstract}

The study aimed to identify the predictive ability of social anxiety in Internet addiction among university students, by relying on the relational descriptive approach. The study sample consisted of (462) male and female students from the Faculty of Educational Sciences at the Hashemite University who were selected through the available random method and were assessed by the social anxiety scale and the Internet addiction scale prepared by Young (1997) which was modified by Widyanto and McMurran (2004) after confirming the appropriateness of its psychometric properties. The study results found that social anxiety level and Internet addiction level were high among the study sample and indicated a statically significant correlation at level (0.01) between the social anxiety level and the level of Internet addiction, which indicates that the higher the social anxiety level, the higher the internet addiction level and that social anxiety works as a predictor of the internet addiction. Results also indicated a nonexistence of statistically significant differences in the social anxiety level as well as the level of Internet addiction due to gender. The current study recommended the activation of students' counseling services for students within the university and society as a whole to train them on controlling and selfcontrol, which reduce the social anxiety and increase the university's interest about Internet addiction phenomenon in addition to holding awareness programs to help solve problems of this phenomenon.

Keywords: Internet addiction, Social anxiety, University students, Predictive ability.

Citation | Bassam Hilal ALHarbi; Salama Aqeel Al-Mehsin; Jaafar Kamel Al-Rababaah; Khaled Ahmed Abdel-Al Ibrahim (2021). The Predictive Ability of Social Anxiety within Internet Addiction among University Students. Journal of Education and e-Learning Research, 8(3): 290-298.

History:

Received: 21 May 2021

Revised: 2 July 202

Accepted: 23 July 2021

Accepted: 23 July 2021

Licensed: This work is licensed under a Creative Commons Attribution 3.0 License $(\mathrm{cc})$

Publisher: Asian Online Journal Publishing Group
Acknowledgement: All authors contributed to the conception and design of the study.

Funding: This study received no specific financial support.

Competing Interests: The authors declare that they have no conflict of interests.

Transparency: The authors confirm that the manuscript is an honest, accurate, and transparent account of the study was reported; that no vital features of the study have been omitted; and that any discrepancies from the study as planned have been explained.

Ethical: This study follows all ethical practices during writing.

\section{Contents}

1. Introduction

3. Theoretical Framework ..292

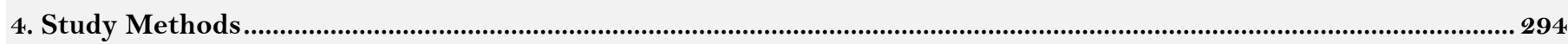

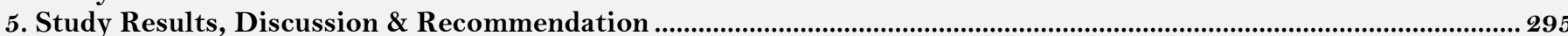

References 


\section{Contribution of this paper to the literature}

This study contributes to existing literature by identifying the predictive ability of social anxiety in Internet addiction among university students.

\section{Introduction}

The social anxiety is considered the most widespread type of disorder in the world after depression and alcoholism, and refers to a fear state of social situations that begins with individuals, due to their lack of social skills, becoming worried in social situations where they face feelings of shame and anger (Goldin et al., 2012).

The main characteristic of social anxiety is the unrealistic fear of negative behavior assessment by others and the cognitive distortion of social situations among socially anxious individuals, who often feel that they are the focus of others' attention more than they actually are and imagine that their surroundings have no other interest other than their constant assessment. Of course, socially anxious individuals imagine that society's assessment of them must be negative which generates poor compatibility and procrastination in the performance of their tasks and make them unable to interact with the educational environment, which negatively affects their academic performance and their true abilities in the courses they study (Al-Naggar, Bobryshev, \& Alabsi, 2013).

University students in the current era spend a lot of time using the Internet, which has become evident in their behavior where they barely move their attention from the devices in their hands (Ahmed \& Santos, 2019) Internet addiction is considered a relatively modern psychological concept. Young (1997) used the term Internet addiction, where she indicated that excessive use of Internet is the closest to addiction even if it didn't match the traits of drug addiction. Students at the university stage are more vulnerable to Internet addiction and any problems that accompanied this addiction which may affect their psychological and social compatibility by increasing their level of social anxiety, therefore affect their adaptation with the educational environment and their academic achievement. The current study tries to reveal the predictive ability of social anxiety within the Internet addiction among a sample of university students.

\subsection{Study Problem \& Questions}

There is no doubt that anxiety is considered one of the important psychological problems that face students in general and university students in particular, because university students in fact face many pressures that lead to anxiety cases that especially happen to them as a result of pressures they face, due to their fears of the future.

Researchers through their work noticed that social anxiety is spreading among university students and impacts their academic performance, and also noticed an increase in Internet addiction among young people and that its spreading rate increases day after day, as well as an increase of its negative effects, especially among youngsters who use it the most for things related to study, work, or leisure time.

Researchers also noticed that with people who are addicted to the Internet, their social media skills are affected.

Given the importance of this category, it becomes necessary to help university students that enjoy appropriate levels of mental health and reduce their Internet addiction. Their social anxiety has an effect where some students become unable to interact with teachers, speak in front of a group, or fail to complete tasks which may lead to isolation and overuse of the Internet, either for wasting time or due to the existence of many variables in it, and here lies the current study problem. Based on this background and in an attempt to find out the predictive ability of social anxiety, and its relationship with Internet addiction and factors associated with it on university students, it's possible to identify the study problems with the following questions:

- What is the level of social anxiety among university students?

- What is the level of Internet addiction among university students?

- Is there a statistically significant relationship at level $(\alpha=0.05)$ between the anxiety level and the Internet addiction level among university students?

- Is it possible to predict the Internet addiction through the social anxiety?

- Are there statistically significant differences at the level $(\alpha=0.05)$ in the social anxiety level among university students, due to gender?

- Are there statistically significant differences at the level $(\alpha=0.05)$ in the Internet addiction level among university students, due to gender?

\section{Study Importance}

The importance of this study lies in the importance of its variables represented in the social anxiety and Internet addiction, and also shows in the importance of its sample represented in the university period which is responsible for shaping students' future, as well as the research for utilizing their capabilities.

The current study attempts to identify the predictive ability of social anxiety and its relationship with Internet addiction. It also attempts to better understand the social anxiety among Hashemite University students as social anxiety is an important variable in shaping the degree of students' interaction during the different social situations, and may be a reason for them to avoid participating in these situations, which negatively affects their social, academic, and professional performance.

It also highlights problems that threaten young people and the risks of using technology among young people. The current study may help to reduce social anxiety and help develop the appropriate mechanisms and programs to prepare, refine, and instill values and provide individuals with the experience and knowledge to become active members in a society of justice and equality. The study can help guide counselors at Jordanian universities to provide preventive and therapeutic programs that increase students' psychological immunity and may contribute to guide researchers of the current topic to conduct other research based on results and tools of this study. Finally, the study may benefit educational policy makers at the Ministry of Education in the Hashemite Kingdom of Jordan, universities, and schools which may enable it to emphasize virtuous values and instill it in youth by using multiple and available methods. 


\section{Theoretical Framework}

Individuals normally strive to reach a sense of happiness as the desired goal in their life, in light of growing challenges and problems, where changes in the cultural, social, economic, and political fields cast a shadow over human thinking and planning for the aspects of their life, which affects them and their level of happiness by achieving themselves and feeling joyful, reassurance, and away from depression and anxiety (Al-Naggar et al., 2013). Transcending emotions to certain limits make individuals in an extreme and urgent situation that may reach sickness, anxiety, depression, and even suicide, therefore our monitoring of negative feelings is the key to emotional health. The violently and irritably emotional extremism leads to loss of personal balance and therefore life moves from its sweet taste to a bitter taste, where the concern about balancing our feelings considers a key task and a basic skill in our lives and in life which everyone must learn (Ahghar, 2014).

\subsection{Social Anxiety}

Anxiety is considered a major aspect of psychological studies in general and mental health in particular; it is a central variable in all mental disorders and behavioral and emotional problems, and a vital variable in the mental health and compatibility at different ages (Ahghar, 2014). The anxiety is expressed as an unpleasant complex emotional state that represents a coalition or a combination of constant fear, panic, terror, constriction, and apprehension as a result of expected imminent evil or a sense of danger and threat from something vague and mysterious, which one cannot objectively show or identify (Asher, Asnaani, \& Aderka, 2017).

The source of this danger or threat that leads individuals to anxiety may be internal, such as conflicts and painful ideas or external, such as fear of expected evils like a natural disaster. The social anxiety presents an anxiety pattern associated with many personality variables, such as low self-esteem, negative thoughts, performance disorder, avoidance behavior, cognitive aspects distortion, low emphasis, and low self-confidence (AlNaggar et al., 2013).

Stein and Waker (2002) defined social anxiety as a observed and continuous fear of one or more social situation or social performance when persons would be exposed to deal with people they do not know or possibly being scrutinized by others (Aksoy, 2018) where individuals will be afraid to act in a manner that may be humiliating or causing (Baltaci, 2019). Social anxiety also defined in the Fourth Diagnostic and Statistical Manual of Disorders issued by the American Psychiatric Association as a noticeable and persistent fear shown by individuals in one or more social or performance situation where through it individuals would be exposed to unfamiliar people (Baltaci, 2019) and carefully viewed and scrutinized by others. Individuals who suffer from social anxiety are afraid of the negative evaluation by others (Goldin et al., 2012) and realize they didn't receive satisfaction and approbation from them but are experiencing humiliation, shame, and confusion in these situations and as a result they avoid social events. The $10^{\text {th }}$ International Classification of Mental Disorders issued by WHO also defines social anxiety as fear of the scrutiny and careful examination of individuals by others, which lead individuals to avoid the social situations and that many individuals' social concerns would be associated with the low self-esteem and fear of criticism also shows that social anxiety is unacceptable fear and avoidance of situations which individuals supposed to deal with or interact with others and as a result will be exposed to some kind of evaluation.

Stangier and Heidenreich (1999) also emphasizes that distinctive key feature of social anxiety represented in the unrealistic fear of negative behavior assessment by others and the cognitive distortion of social situations through the social anxiety. Fikabovid and Koir (2008) stressed that social anxiety means a lack of social skills, a negative feeling of individuals toward themselves, and the confusion of social fear. Social anxiety has been divided into two types; the first one is a general social anxiety that includes fear of falling into embarrassing situations, especially social, while the other type is a specific social anxiety which associated with fear of one or more of the social situations. Social anxiety also defined as an emotional, cognitive, behavioral response to social situations that perceived as a self-threatening (Al-Naggar et al., 2013) and social anxiety may appear as a result of a complex interaction between the environmental and biological factors, which include the inherited characters, where anxiety disorders tend to spread among members of the same family.

However, it's not entirely clear how much of this can be traced back to genes and how much can be traced back to the learned behavior (Ahghar, 2014; Al-Naggar et al., 2013). The abnormal parental treatment methods based on high levels of excessive control and protection, and controls and restrictions imposed on children who prevent them from being exposed to social situations may contribute to the emergence of social anxiety (Al-Naggar et al., 2013). In addition, the relationships between social anxiety and peer relationships are mutual, where the socially anxious children are more likely to experience negative relationships with peers compared to ordinary children, where these experiences lead to the deterioration and continuity of their social anxiety (Goldin et al., 2012).

Social anxiety disorder involves fear, apprehension, and avoidance of what interferes with the daily routine, work, school, or other activities. Social anxiety disorder usually begins in the early years to mid-adolescence, even though sometimes it begins in younger children or adults (Ahmad, 2009; Ahmed \& Santos, 2019). It's possible for individuals to avoid performance situations or scary social situations with the existence of severe and continuous psychological tension, anxiety, and distress. Fear or anxiety may be inconsistent with the actual threat represented by the current social situation or the socio-cultural context. Fear or anxiety and avoidance may be continuous among individuals for six months or more. It's also possible for avoidance and expectation of anxiety and disdain in performance or social situations to conflict with academic and professional jobs, social activities, and the relationship with others.

There are those who view social anxiety as genetic readiness as in the biological theory, and there are those who see it as instinctive lyrical tendencies repressed in the subconscious which were removed from their original subject to an alternative and symbolic subject as in the psychoanalysis theory (Ahghar, 2014). There are also those who see it as educated habits and behaviors that were acquired and learned through the painful conditional experiences and through modeling process and lack of social skills among individuals, as in the behavioral theory, or as a result of false and abnormal cognitive processes as in the cognitive theory. 


\subsection{Internet Addiction}

The problem of Internet addiction has emerged as a modern social issue with the growing popularity of Internet, and countries around the world have been concerned with the Internet addiction problem (Anderson, 2001) and showed an increase in the realistic observation of growing tendency to use the Internet by students (Widyanto \& McMurran, 2004). The interest in studying Internet addiction has also increased as a phenomenon that has spread among individuals in different societies, which may return to the multiple psychological, social, and health effects that have an impact on people who use this network.

The Internet users continue to spend more time online, and naturally give less time to other activities and other people in their lives, while overlooking the significant role it play in their life where it transmit a huge amounts of information between persons of human race at an amazing speed and made the world a small cosmic village where people interact with each other (Ahmed \& Santos, 2019). There are many symptoms of internet addiction, which include a steady increase in the number of online hours that exceed the periods set by individuals for themselves (Kürşad, Çutuk, Soyer, Akkuş, \& Aydoğan, 2020) and the extreme stress and anxiety in the existence of any barrier for network connectivity that may reach the point of depression if the Internet cutoff stayed for long period, and feeling very happy and psychologically comfortable whenever Internet comes back on (Azher, Khan, \& Salim, 2014). The negligence of social, family, and job duties due to the use of network, in addition to talking about the Internet in everyday life and continuously using the Internet in spite of some problems, such as loss of social relationships and being late for work, as well as suddenly waking up and having the desire to open email or see the list of callers on social media (Ahmed \& Santos, 2019).

Internet addiction has many health effects, such as the damage to hands from excessive use, eye damage as a result of the radiation transmitted by computer or telephone screens, spinal and leg damage as a result of seating type and length, ear damage for headphone users, and associated damage such as obesity and its accompanying diseases. The psychological effects due to the excessive use of Internet, which includes the entrance to an alternative imaginary world offered by the Internet causes enormous psychological effects where the reality is mixed with illusion (Akm, 2017) and the reduction of individuals' ability to create a straight psychological personality capable of interacting with living society and reality. In addition, there are social effects for internet addicts such as the noticeable withdrawal of human beings from social interaction towards isolation, the impact on cultural identity, customs, and values with this massive information invasion, the loss of real friends, the weakness of family control over children, and the breakup of family.

The researchers' interest in education and psychology recently; and in light of the COVID-19 spread has focused on examining an important variable, such as social anxiety as a variable that has an impact on people's lives, as well as people focus on using the Internet to extract information and track news, which has affected individuals in general and the student class in particular, especially since learning has become electronic. Therefore, many researchers have examined the social anxiety topic from different respects, and here are some of the studies that addressed the social anxiety among the university students Buckner and Schmidt (2009); Carleton, Collimore, and Asmundson (2010); Higa, Phillips, Chorpita, and Daleiden (2008); Mustafa, Özteke, and Ahin (2018); Shand, Degenhardt, Nelson, and Mattick (2010) and Kürşad et al. (2020) while other researchers have gone on to study the social anxiety among school students, such as Alshehri, Azahrani, and Alotaibi (2015); Tras and Gökçen (2020) and Seong, Hwang, and Ja (2005).

Results of Carleton et al. (2010); Shand et al. (2010)'s study indicated a high degree of anxiety, while the study results of Mustafa et al. (2018); Dorani, Elhadif, Bukovza, Yarmulnik, and Dannon (2015) indicated a medium degree of anxiety among study members. There are differences between males and females with regard to social anxiety, while differences in social anxiety were in favor of females, as in the study of Onwuegbuzie (2004) while the study of Kürşad et al. (2020); Mustafa et al. (2018); Tras and Gökçen (2020) indicated no differences in social anxiety between males and females.

There is also a direct correlation between the high level of social anxiety and some social variables, such as the use of technology and the low level of achievement as indicated by the study results of Dell'Osso et al. (2003). With regard to the widespread of Internet addiction, the results of Alshehri et al. (2015) study indicated that Internet addiction is a common problem with about (45.3\%) of students who suffer from the Internet addiction, as the study sample. The study results of Kürşad et al. (2020); Dorani et al. (2015) also indicated a correlation between the Internet addiction and social anxiety and the nonexistence of differences in the addiction degree between males and females (Mustafa et al., 2018) and this confirmed by the study results of Harman, Hansen, Cochran, and Lindsey (2005) which indicated a correlation between Internet addiction and the high level of social anxiety and violence.

The results of Seong et al. (2005) study indicated a relationship between social anxiety and the number of hours using Internet but indicated a nonexistence of differences between males and females in the level of social anxiety, and that variables of sex, utilization period, and age group were epidemics of social anxiety. The study results of Shand et al. (2010); Tras and Gökçen (2020) indicated that number of hours spent using the Internet deepens level of social anxiety among individuals.

It's clear from the above that there is a scarcity in the studies that addressed the direct relationship between social anxiety prediction and the Internet addiction, while the relationship of the social anxiety variable with several variables or a single variable has been studied, such as the study of Carleton et al. (2010) which addressed the relationship between social anxiety variable and non-confirmed behavior, the study of Shand et al. (2010) addressed the social anxiety prediction factors, the study of Mustafa et al. (2018) addressed the differences between gender in social relationships and Internet addiction. The study of Buckner and Schmidt (2009) addressed the impact of social anxiety on the balance but the study of Bernstein, Bernat, Davis, and Layne (2008) focused on symptoms of social anxiety and the study of Higa et al. (2008) examined the relationship of social anxiety with selfawareness. Harman et al. (2005) study addressed the relationship of social anxiety with Internet use, while the study of Seong et al. (2005) addressed the psychological symptoms associated with social anxiety and its relationship with the Internet addiction, and the study of Ferda, Gamze, Orhan, and Nesim (2004) focused on the prevalence ratio of social anxiety and its relationship with both of body image and self-esteem. The study of Dell'Osso et al. (2003) examined the social anxiety disorder, while the study of Loudin, Loukas, and Robinson 
(2003) addressed the role of empathy and social anxiety on the relational violence, and the study of Onwuegbuzie (2004) investigated the relationship between social anxiety and the academic procrastination. The study of Tras and Gökçen (2020) examined the relationship between academic procrastination and social anxiety, and Internet use, while the study of Mustafa et al. (2018) addressed the gender differences in social relationships and the Internet addiction.

\section{Study Methods}

Researchers adopted the relational descriptive approach due to its appropriateness with the study objectives.

\subsection{Study Population EO Sample}

The study population consisted of all $(1,628)$ male and female students from the Faculty of Educational Sciences at the Hashemite University, according to the statistics of Admissions and Registration Unit for the academic year (2020/2021) from the first semester, while the study sample consisted of (462) male and female students selected in the available way, and selected (462) electronic answers that include the two study tools and were acceptable for statistical analysis out of (495) electronic questionnaires sent via email.

\subsection{Study Instrument}

The current study relied on the use of two instruments using the social anxiety scale prepared by researchers, and the Internet addiction scale prepared by (Young) and modified by Widyanto and McMurran (2004) which can be detailed as follows:

\section{First: Social Anxiety}

Validity: to verify the content validity of study instrument and to ensure that it serves the study objectives, researchers presented it to a group of (10) experienced and specialized arbitrators from the educational psychology and measurement and evaluation faculties of Jordanian universities, to benefit from their observations and experiences to arbitrate the instrument and ensure its items include the area of attribute to be measured and to ensure the integrity of language formation, and the clarity and non-duplication of items. Arbitrators were asked to judge the suitability level of each item to the characteristic to be measured, represented in the social anxiety, as well as to judge the clarity of item in terms of language formulation and correctness, and to suggest alternatives to items, improve it, delete it, or modify it. In light of the advices and suggestions of arbitrators, all items that received the agreement of arbitrators by $(80 \%)$ or more have been retained, and after deleting 4 items which got less than $(80 \%)$ of arbitrators agreement, the number of items become (36) at the final form of instrument, and had the validity of arbitrators. In order to verify the validity of internal consistency of instrument's items and ensure the statistical validity of items by implementing it on a survey sample of (30) male and female students from outside the study sample, and calculated the correlation of each item's degree with the overall degree, where all correlation values were acceptable and ranged between (0.48-0.69) which is statistically significant correlations at the level (0.01), and indicate the availability of internal consistency validity of items.

Reliability: to verify the reliability of study instrument, researchers calculated the reliability of instrument by using the Cronbach Alpha Coefficient equation, as well as calculating the Split Half reliability Coefficient method using Spearman/ Brown equation. The questionnaire was implemented after the step of making arbitrators' adjustments on a survey sample of (30) for the purposes of verifying the instrument's reliability, where the overall reliability coefficient of instrument by using Cronbach Alpha method amounted to (0.88) and reached (0.836) by using the Split Half Spearman/ Brown method. Therefore, it can be concluded that questionnaire has a high degree of reliability and is appropriate and valid for implementation on the study sample.

Correction of social anxiety scale items: all items formulated in the negative direction of social anxiety scale, where the high degree indicates a high degree of social anxiety and the low degree indicates a low degree of social anxiety (Always, often, sometimes, rarely, never) according to the Likert Fifth Scale to estimate the degree of social anxiety disability. The range of response levels of (5) and by dividing the range on the number of assessment levels for the anxiety existence degree that equal to 5 , the division result $=0.80$, which represent the category length, therefore the criterion for judging the anxiety existence degree became as follows (very few: 1-less than 1.80, Few: 1.81-less than 2.60, medium: 2.61-less than 3.40, high: 3.41-less than 4.20, and very high: 4.21-5).

\section{Second: Internet Addiction}

To achieve the study's objectives, researchers obtained the internet addiction scale (Young, 1997) modified by Widyanto and McMurran (2004) which consists of (20) items. In order to implement this scale in the current research, researchers translated it and presented it on a group of arbitrators in the field of educational psychology at the Hashemite University to take with their opinions, in order to confirm the appropriateness degree of items and mention the six alternatives of scale as well as the appropriateness of scale's instructions.

Validity: to verify the content validity of study instrument and to ensure that it serves the study objectives, researchers presented it to a group that consists of (10) experienced and specialized arbitrators from the educational psychology and measurement and evaluation faculties of Jordanian universities, to benefit from their observations and experiences to arbitrate the instrument, check the authenticity of translation, and ensure its items include the area of attribute to be measured, as well as to ensure the integrity of language formation and the clarity and non-duplication of items.

Arbitrators were asked to judge the belonging level of each item to the characteristic to be measured, represented in the Internet addiction, as well as to judge the clarity of item in terms of language formulation and correctness, and to suggest alternatives to items, improve it, delete it, or modify it. In light of the advices and suggestions of arbitrators, all (20) items have been retained and then calculated the correlation of each item's degree with the overall degree, where all correlation values were acceptable and ranged between (0.65-0.91) which is statistically significant correlations at the level (0.01), and indicate the availability of internal consistency validity of items. Researchers calculated the correlations coefficient degree of the six scale fields to the total degree of 
Internet addiction scale, where the phenomenon prominence field amounted to (0.93), field of overuse (0.93), field of work refusal (0.88), field of expectation (0.85), lack of control field (0.84), and the rejection of social life field (0.82).

Reliability: to verify the reliability of study instrument, researchers calculated the reliability of instrument by using the Cronbach Alpha Coefficient equation, as well as calculating the Split Half Reliability Coefficient method using Spearman/ Brown equation. The questionnaire was implemented after the step of making arbitrators' adjustments on a survey sample of (30) for the purposes of verifying the instrument's reliability, where the overall reliability coefficient of instrument by using Cronbach Alpha method amounted to (0.92) and reached (0.90) by using the Split Half Spearman/ Brown method. Therefore, it can be concluded that questionnaire has a high degree of reliability and is appropriate and valid for implementation on the study sample.

Correction of Internet addiction scale: the scale designed by placing five alternatives in front of each item, which are (apply to me completely, apply to me, apply to me to some extent, doesn't apply to me, doesn't apply to me completely), and for the purpose of correcting scale the answers above meets with a grading scale $(1,2,3,4,5)$ and for all items, where the overall score per person will be calculated on this scale by the forced addition of its responds' degrees on items.

\section{Study Results, Discussion \& Recommendation 5.1. Results}

Results related to the first question: What is the level of social anxiety among university students? Researchers calculated the social anxiety level among the Hashemite University students, where the arithmetic means amounted to (4.11) and the standard deviation (0.985) at a high degree of social anxiety level.

Results related to the second question: What is the level of Internet addiction among university students? Researchers calculated the Internet addiction level among the Hashemite University students, where the arithmetic means amounted to (4.09) and the standard deviation (1.103) at a high degree of Internet addiction level.

Results related to the third question: Is there a statistically significant relationship at level $(\alpha=0.05)$ between the anxiety level and Internet addiction level among university students? Researchers calculated the correlation between anxiety level and the level of Internet addiction, which amounted to (0.743) at a significant level of (0.01) and this result indicates a statistically positive correlation at the level (0.01) between the social anxiety level and the level of Internet addiction, which means a higher level of social anxiety leads to a higher level of Internet addiction.

Results related to the fourth question: Is it possible to predict the Internet addiction through the social anxiety? To analyze this question statistically, researchers used the multiple regression analysis by using the "Enter" method to determine the impact level of social anxiety on the Internet addiction, where Tables 1 and Table 2 below show the results of this statistical analysis.

Table-1. Results of variation analysis between the social anxiety and Internet addiction.

\begin{tabular}{c|c|c|c|c|c}
\multicolumn{6}{c}{ Table-1. Results of variation analysis between the social anxiety and Internet addiction. } \\
\hline Source & SS & DF & MS & F & Sig \\
\hline Regression & 774.713 & 4 & 193.678 & 5.166 & 0.001 \\
\hline Error & 8697.389 & 232 & 37.489 & & \\
\hline Total & 9472.101 & 236 & & & \\
\hline Note: *** Significant value at level 0.001.
\end{tabular}

Table-2. Results of multiple regressions, multi-correlation, the coefficient of determination for multi-regression model between social anxiety and Internet addiction and its statistical significance of social anxiety.

\begin{tabular}{c|c|c|c|c|c|c|c|c}
\hline Strategy & $\mathbf{R}$ & Std. Error & Std. R & T-value & Sig & $\mathbf{R}^{\prime}$ & $\mathbf{R}^{\mathbf{2}}$ \\
\hline Constant & 14.617 & 5.917 & & $4.681^{* * *}$ & 0.000 & 0.286 & 0.082 \\
\hline Social Anxiety & 0.911 & 0.225 & 0.374 & $7.243^{* * *}$ & 0.000 & & \\
\hline
\end{tabular}

Table 2 shows that multiple regression model between Internet addiction (Y) and social anxiety $(\mathrm{X})$ can be formulated in the following equation:

Estimated regression model:

$\mathrm{X} 0.9110 .085+14.617=\mathrm{Y}$

This regression model indicates:

- $\quad$ Fixed amount $=14,617$

- $\quad$ Regression Coefficient $=0.911$

- $\quad$ Validity of the estimated regression model: the validity of the estimated regression model can be judged by commenting on the multiple regression results of social anxiety illustrated in Table 1 and Table 2 as follows:

- $\quad$ Explanatory capability of model: Table 2 indicates that multiple correlation coefficient (R) is equal to (0.286) and that $\mathrm{R}$ squared coefficient $\left(\mathrm{R}^{2}\right)$ is equal to (0.082), which means that social anxiety explains $(8.2 \%)$ of changes that have occurred in the dependent variable represented in the Internet addiction, and the remaining $(91.8 \%)$ of the variation returned to other factors, therefore the interpretive capability of model considers inappropriate because it is less than $(50 \%)$ of the students' Internet addiction variation.

- Overall statistical significance of model: Table 1 which includes variation analysis indicates that statistical significance value (Sig) is equal to (0.001), which is below the significant level of (1\%), therefore the regression model is statistically significant and it's possible to use the estimated regression model to predict the students' Internet addiction.

- Partial statistical significance of model: Table 2 which includes multiple regression coefficient, and its statistical significance shows that coefficients were as follows: fixed value in the equation is equal to (14.617) which is significant at level (0.01), therefore the existence of this constant in the estimated equation is essential and substantial. It also noticed that regression coefficient of (0.911) is statistically significance, and this result indicates that social anxiety is appropriate to be used as a predictor of Internet addiction. 
Results related to the fifth question: Are there statistically significant differences at the level $(\alpha=0.05)$ in the social anxiety level among university students, due to gender?

\begin{tabular}{|c|c|c|c|c|c|}
\hline Gender & Number & Mean & STDEV & T-value & Seg \\
\hline Male & 229 & 4.11 & 0.673 & \multirow{2}{*}{0.965} & \multirow{2}{*}{0.654} \\
\hline Female & 233 & 4.13 & 0.721 & & \\
\hline
\end{tabular}

Table 3 shows nonexistence of statistically significant differences at the social anxiety level among the Hashemite University students, due to gender.

Results related to the fifth question: Are there statistically significant differences at the level $(\alpha=0.05)$ in the Internet addiction level among Hashemite university students, due to gender?

Table-4. Differences at the Internet addiction level among Hashemite University students, due to gender.

\begin{tabular}{c|c|c|c|c|c}
\hline Gender & Number & Mean & STDEV & T-value & Seg \\
\hline Male & 229 & 4.03 & 0.681 & \multirow{2}{*}{0.743} & \multirow{2}{*}{0.562} \\
\hline Female & 233 & 4.05 & 0.694 & & \\
\hline Note: *** Significant value at level 0.001.
\end{tabular}

Table 4 shows nonexistence of statistically significant differences at the Internet addiction level among the Hashemite University students, due to gender.

\subsection{Discussion}

Results showed that the social anxiety level among university students was at a high degree, which can be explained due to the students' cognitive, behavioral, and emotional responses to the social situations. The result can also be explained by the large time students spent on their study or by generating a medium shortage in the encryption and encoding of environmental incentive, which creates a tendency about their interpretation of mysterious events negatively and makes their anxiety high. This may return to the nature of circumstances that world as whole and our society in particular go through, in light of the spread of Covid 19 and its accompanying health precautions which may raise the social anxiety of all society members in general and university students in particular (Aksoy, 2018). The social anxiety of sample members can be considered high, and researchers attributed this result to the events that students face in their lives, which may be represented in the restrictions imposed by the family on students, especially in the difficult circumstances that Kingdom of Jordan is going through due to the epidemic circumstance, which has cause students to lose some of the self-confidence and the positive self-esteem. Bearing in mind that beginning of the emergence of social anxiety happened early, it's possible to explain its presence among students due to the family factors and experiences, where children learn a lot about the social relationships with others through their parents. Most anxieties are acquired and children are not born worried, but they learn anxiety from the surrounding environment and from individuals who live with them, especially parents and if parents themselves are socially anxious, their children acquire this social anxiety and the avoidance through the modeling process (Asher et al., 2017). The result agrees with the study results of Carleton et al. (2010); Shand et al. (2010) which indicated a high degree of social anxiety.

Results showed that the Internet addiction level among students of Hashemite University was at a high degree, which is a logical result because access to the Internet is becoming affordable, and a presence on the Internet is available at most institutions, companies, schools, and universities and the movement between websites and the access to social media and chatting became an activity practiced by young and old people alike. It's possible to say that current result is the result of current era of technology. The Corona pandemic and the resulting closures and bans also encouraged Internet addiction behaviors and led all individuals to try to fill their time by accessing the Internet, which increased the hours of use and changed the behavior of individuals, in general and university students in particular. The motivation for using and being addicted to the Internet from students may be for pleasure, relaxation, and entertainment or may be the reason to establish social relationships between student groups. The excessive internet addiction and use among students may create different social and psychological disorders that increase other burdens on the educational institution.

The result indicates that social anxiety is appropriate to be used as a predictor for Internet addiction, where social anxiety is one of the factors that increases the Internet addiction level and that male and female students with high level of Internet addiction have a much higher level of social anxiety, because social anxiety is a cognitive, behavioral, and emotional response accompanied by feelings of social distress, social avoidance, and a fear of negative assessment.

The male and female students with a high level of Internet addiction cognitively characterized with selfcentered attention and have a lack of encryption and encoding of environmental thrills and motives, and those individuals of social anxiety also have a tendency to interpret mysterious events negatively. They're exaggerating the possibility of whatever happen to them of negative outcomes, and also exaggerate the possibility of others to observe their psychological distress in the social situation and they are pretty much formulate a negative mental image. The results of this study agree with study results of Harman et al. (2005).

The results show no statistically significant differences at the Internet addiction level among students of Hashemite University, due to gender and this result may return to the easy Internet access among university students through their access to websites and the availability of computers and mobile devices, the latter will be the most present with students. In addition, the motivation for using the Internet among students and their addiction to it is a factor of pleasure and refreshment or may be the reason to establish social relationships between students' categories. The excessive Internet addiction among students may create different social and psychological diseases that increase other burdens on the educational institution and Internet addiction may satisfy the desire of learners (Azher et al., 2014). 
The Internet provides various websites that attract beneficiaries to it by satisfying their emotional, aesthetic, luxury, and commercial characters and instincts, which cause them to be subconsciously addictive by being connected to the Internet. The Internet addiction among young people may contribute to various psychological diseases, such as mistrust, shyness, lack of self-reliance, suffering from feelings of guilt, loss of entrepreneurship, and feeling unable to perform the normal daily tasks assigned to them (Akın, 2017). There are also nonexistence of statistically significant differences at the Internet addiction level among the Hashemite university students, due to gender and it appears from the result that students who have the desire to be addicted to the Internet and will use the Internet for long hours, regardless of their social type or gender will find the necessary time to meet their full needs satisfied by the Internet use. The current findings agree with the study results of Kürşad et al. (2020); Mustafa et al. (2018); Tras and Gökçen (2020) where its results indicated nonexistence of differences in the social anxiety, due to gender.

\subsection{Recommendation}

- Activate the counseling services for students inside the university and the society as a whole, which train them on control and self-control, which reduce the social anxiety.

- Provide the rehabilitation, counseling, and guidance courses and sessions for students to develop their selfconfidence, and benefit from their capabilities and general characteristics, which reduce their psychological and social anxiety.

- Increase the university's interest in the phenomenon of Internet addiction and hold the awareness programs to help solve problems of this phenomenon.

- Conduct additional studies on the research topic, where results of this study remain limited within the research sample in order for results to be optimally generalized.

\section{References}

Ahghar, G. (2014). Effects of teaching problem solving skills on students' social anxiety. International Journal of Education and Applied Sciences, $1(2), 108-112$

Ahmad, N. (2009). Academic achievement and its relationship with social anxiety and self-esteem in male and female school students. PhD Thesis, University of the Punjab, India.

Ahmed, S., \& Santos, M. G. (2019). Cyber mania secondary to Internet addiction: A brief review on co-occurrence of behavioral addiction and bipolar disorder-dual diagnosis. Eurasian Journal of Medicine and Oncology, 3(4), 296-299.

Akın, M. (2017). A research on the impacts of the young people's Internet addiction levels and their social media preferences. International Review of Management and Marketing, 7(2), 256-262.

Aksoy, M. E. (2018). A qualitative study on the reasons for social media addiction. European Journal of Educational Research, 7(4), 861-865. Available at: https://doi.org/10.12973/eu-jer.7.4.861.

Al-Naggar, R. A., Bobryshev, Y. V., \& Alabsi, M. (2013). Perfectionism and social anxiety among university students in Malaysia. ASEAN Journal of Psychiatry, 14(1), 1-8.

Alshehri, A., Azahrani, H., \& Alotaibi, M. (2015). Internet addiction among Taif University students and its association with psychiatric comorbidities. Merit Research Journal of Medicine and Medical Sciences, 3(12), 536-544.

Anderson, K. J. (2001). Internet use among college students: An exploratory study. Journal of American College Health, 50(1), 21-26. Available at: https://doi.org/10.1080/07448480109595707.

Asher, M., Asnaani, A., \& Aderka, I. M. (2017). Gender differences in social anxiety disorder: A review. Clinical Psychology Review, 56(1), 1-12. Available at: https://doi.org/10.1016/j.cpr.2017.05.004.

Azher, M., Khan, R. B., \& Salim, M. (2014). The relationship between internet addiction and anxiety among students of University of Sargodha. International Journal of Humanities and Social Science, 4(1), 288-293.

Baltaci, Ö. (2019). The predictive relationships between the social media addiction and social anxiety, loneliness, and happiness. International Journal of Progressive Education, 15(4), 73-82. Available at: https://doi.org/10.29329/ijpe.2019.203.6.

Bernstein, G. A., Bernat, D. H., Davis, A. A., \& Layne, A. E. (2008). Symptom presentation and classroom functioning in a nonclinical sample of children with social phobia. Depression and Anxiety, 25(9), 752-760. Available at: https://doi.org/10.1002/da.20315.

Buckner, J. D., \& Schmidt, N. B. (2009). Social anxiety disorder and marijuana use problems: The mediating role of marijuana effect expectancies. Depression and Anxiety, 26(9), 864-870. Available at: https://doi.org/10.1002/da.20567.

Carleton, R. N., Collimore, K. C., \& Asmundson, G. J. (2010). "It's not just the judgements-It's that I don't know": Intolerance of uncertainty as a predictor of social anxiety. Journal of Anxiety Disorders, 24(2), 189-195. Available at: https://doi.org/10.1016/j.janxdis.2009.10.007.

Dell'Osso, L., Rucci, P., Ducci, F., Ciapparelli, A., Vivarelli, L., Carlini, M., \& Cassano, G. B. (2003). Social anxiety spectrum. European Archives of Psychiatry and Clinical Neuroscience, 253(6), 286-291.

Dorani, D., Elhadif, R., Bukovza, Y., Yarmulnik, A., \& Dannon, P. (2015). Internet addiction is associated with social anxiety in young adults. Annals of Clinical Psychiatry, 27(1), 4-9.

Ferda, I., Gamze, A., Orhan, D., \& Nesim, K. (2004). Social phobia among university students and its relation to self-esteem and body image. The Canadian Journal of Psychiatry, 49(9), 630-634 Available at: https://doi.org/10.1177/070674370404900910.

Fikabovid, P., \& Koir, E. (2008). Social phobia. Clinical Psychology Review, 27, 147-147.

Goldin, P. R., Ziv, M., Jazaieri, H., Werner, K., Kraemer, H., Heimberg, R. G., \& Gross, J. J. (2012). Cognitive reappraisal self-efficacy mediates the effects of individual cognitive-behavioral therapy for social anxiety disorder. Journal of Consulting and Clinical Psychology, 8O(6), 1034-1040. Available at: https://doi.org/10.1037/a0028555.

Harman, J. P., Hansen, C. E., Cochran, M. E., \& Lindsey, C. R. (2005). Liar, liar: Internet faking but not frequency of use affects social skills, self-esteem, social anxiety, and aggression. Cyber Psychology \& Behavior, 8(1), 1-6. Available at: https://doi.org/10.1089/cpb.2005.8.1.

Higa, C. K., Phillips, L. K., Chorpita, B. F., \& Daleiden, E. L. (2008). The structure of self-consciousness in children and young adolescents and relations to social anxiety. Journal of Psychopathology and Behavioral Assessment, 30(4), 261-271. Available at: https://doi.org/10.1007/s10862-008-9079-z.

Kürşad, S., Çutuk, S., Soyer, F., Akkuş, Ç. Z., \& Aydoğan, R. (2020). Mediating role of emotion regulation difficulties in the relationship between social anxiety and problematic Internet use. Psychology, 53(3), 291-305. Available at: https://doi.org/10.2298/psi190730013s.

Loudin, J. L., Loukas, A., \& Robinson, S. (2003). Relational aggression in college students: Examining the roles of social anxiety and empathy. Aggressive Behavior: Official Journal of the International Society for Research on Aggression, 29(5), 430-439. Available at: https://doi.org/10.1002/ab.10039.

Mustafa, B., Özteke, R., \& Ahin, K. (2018). Gender differences in and the relationships between social. Journal of Medical Internet Research, $20(1), 253-262$.

Onwuegbuzie, A. J. (2004). Academic procrastination and statistics anxiety. Assessment छ Evaluation in Higher Education, 29(1), 3-19. Available at: https://doi.org/10.1080/0260293042000160384. 
Seong, J., K., Hwang, S., \& Ja, Y. C. (2005). Adolescents internet addiction and psychiatric symptoms Among Korean. Journal of Clinical Psychology, 13(4), 426430. Available at: 10.1111/j.1746-1561.2007.00279.x.

Shand, F. L., Degenhardt, L., Nelson, E. C., \& Mattick, R. P. (2010). Predictors of social anxiety in an opioid dependent sample and a control sample. Journal of Anxiety Disorders, 24(1), 49-54. Available at: https://doi.org/10.1016/j.janxdis.2009.08.010.

Stangier, U., \& Heidenreich, T. (1999). The social phobia from a cognitive-behavioral perspective. In J. Margraf \& K. Rudolf (Eds.), Soziale Kompetenz, Soziale Phobie. Anwendungsfelder, Entwicklungslinien, Erfolgsaussichten (2nd ed., pp. 40-60). Baltmannsweiler: Schneider-Verlag, Hohengehren.

Stein, M., \& Waker, J. (2002). Triumph overshyness: Conquering shyess and social anxiety. New york: Me Goaw- Hill.

Tras, Z., \& Gökçen, G. (2020). Academic procrastination and social anxiety as predictive variables internet addiction of adolescents. International Education Studies, 13(9), 23-35. Available at: https://doi.org/10.5539/ies.v13n9p23.

Widyanto, L., \& McMurran, M. (2004). The psychometric properties of the internet addiction test. Cyber Psychology \& Behavior, 7(4), 443450. Available at: https://doi.org/10.1089/cpb.2004.7.443.

Young, K. (1997). What makes the internet addiction: Potential explanations for psychological internet use? Paper presented at the Annual Meeting of the American Psychological Association, II. August. 